Bond University

Research Repository

\title{
Family carers' perspectives of managing activities of daily living and use of mHealth applications in dementia care: A qualitative study
}

Rathnayake, Sarath; Jones, Cindy; Calleja, Pauline; Moyle, Wendy

Published in:

Journal of Clinical Nursing

DOI:

10.1111/jocn. 15030

Licence:

Other

Link to output in Bond University research repository.

Recommended citation(APA):

Rathnayake, S., Jones, C., Calleja, P., \& Moyle, W. (2019). Family carers' perspectives of managing activities of daily living and use of mHealth applications in dementia care: A qualitative study. Journal of Clinical Nursing, 28(23-24), 4460-4470. https://doi.org/10.1111/jocn.15030

\section{General rights}

Copyright and moral rights for the publications made accessible in the public portal are retained by the authors and/or other copyright owners and it is a condition of accessing publications that users recognise and abide by the legal requirements associated with these rights.

For more information, or if you believe that this document breaches copyright, please contact the Bond University research repository coordinator 
MR. SARATH RATHNAYAKE (Orcid ID : 0000-0003-2379-1610)

Article type : Original Article

Family carers' perspectives of managing activities of daily living and use of mHealth applications in dementia care: A qualitative study

Running title: Functional care and mHealth apps in dementia

\section{Authors}

Sarath Rathnayake RN, MScN (Res), PhD candidate ${ }^{1,2,3}$

Cindy Jones $\mathrm{PhD}^{1,4}$

Pauline Calleja RN, $\mathrm{PhD}^{1,2}$

Wendy Moyle RN, PhD ${ }^{1,2}$

${ }^{1}$ Menzies Health Institute Queensland, Griffith University, Australia

${ }^{2}$ School of Nursing and Midwifery, Griffith University, Australia

${ }^{3}$ Department of Nursing, Faculty of Allied Health Sciences, University of Peradeniya, Sri

Lanka

${ }^{4}$ Faculty of Health Sciences and Medicine, Bond University, Australia

\section{Corresponding author:}

Mr. Sarath Rathnayake, School of Nursing and Midwifery, Nathan Campus, Griffith

University, 170 Kessels Rd, Nathan QLD 4111, Australia. Email:

sarath.rathnayake@griffithuni.edu.au. Telephone: +61405374522

This article has been accepted for publication and undergone full peer review but has not been through the copyediting, typesetting, pagination and proofreading process, which may lead to differences between this version and the Version of Record. Please cite this article as doi: 10.1111 jocn.15030

This article is protected by copyright. All rights reserved. 


\section{Acknowledgements}

The research team gratefully acknowledges the carers who participated in this study. This study was conducted as a part of the first author's PhD study. His PhD study was supported by a Griffith University International Post Graduate Research Scholarship and Griffith University Post Graduate Research Scholarship.

\section{Declaration of conflicting interests}

The authors declare no potential conflicts of interest with respect to the research, authorship, and/or publication of this article.

\section{Funding}

This research received no specific grant from funding agencies in the public, commercial, or not-for-profit sectors.

\section{Authors' contributions}

Conception and design: SR, WM \& CJ. Acquisition of data: SR. Data analysis and interpretation: SR, CJ, WM \& PC. Manuscript preparation and the first draft of the manuscript: SR. Critical review and editing of the manuscript: CJ, WM \& PC. All authors have read and approved the final manuscript.

\section{Abstract}

\section{Aim}

This qualitative study examined the needs, barriers and challenges experienced by family carers of people with dementia concerning the management of their care recipients' 
functional disabilities, and their experiences and opinions of using mobile health (mHealth) applications in health information seeking.

\section{Background}

Functional disability is a significant problem among people with dementia and management can be challenging for family carers. Evidence suggests that mHealth applications can support knowledge needs of patients and families.

\section{Design}

A qualitative descriptive exploratory study.

\section{Methodology}

In-depth interviews were conducted with a purposive sample of family carers using a semistructured interview guide. An inductive thematic analysis method was used. The COREQ reporting guideline was followed.

\section{Results}

Five spousal and five child carers participated in this study. Four key themes were identified:

(1) Challenges faced that contribute to psychological distress and burden; (2) Essential role of support systems in dementia care; (3) Information and educational needs of family carers, and (4) Experiences and attitudes of mHealth applications as an educational and supportive resource.

This article is protected by copyright. All rights reserved. 


\section{Conclusion}

Providing functional care is demanding, challenging and stressful, and leads to carer burden. The complexity of dementia is a barrier in the organisation of functional care and access to a support network is vital to care provision. The information needs of family carers can potentially be addressed through an mHealth application.

\section{Relevance to clinical practice}

This study provides important information on family carers' needs, and the barriers and challenges related to functional care for people with dementia. Findings from this study can assist nurses and other health professionals in the planning of educational and supportive programs for family carers. Furthermore, the use of mHealth applications could positively contribute to the delivery of these programs.

Keywords: functional disability, dementia, family carers, mHealth applications

\section{Introduction}

Dementia is a chronic health problem in older age that leads to disability and dependency. Due to the complex nature and high demand for care, dementia can negatively affect the person with dementia, their carers and society. In dementia care, family caregiving is a critical component as the majority of people with dementia live in the community and rely on family members for support. Families are recognised as experts in supporting a person with a chronic condition (Bamm \& Rosenbaum, 2008). However, the role of family carers is very complex and diverse, as they have to manage the impact of the situation on the family while fulfilling the needs of their care recipients (Cabote, Bramble, \& McCann, 2015). 
Informal carers of people with dementia work long hours and may provide 40 or more hours of care per week in the community (Australia Institute of Health and Welfare, 2012).

\section{Background}

Functional decline is a considerable problem for people with dementia. Usually, deterioration in the basic activities of daily living (BADLs) (e.g. bathing and toileting), is significant in the late stages of dementia while decline in complex activities, referring to instrumental activities of daily living (IADLs) (e.g. using telephone and managing finance), starts in the early stages (Mlinac \& Feng, 2016). Providing care for a person's functional disabilities is complex, requires long hours, and carers often face several challenges (Brodaty \& Donkin, 2009). Additionally, the caregiving process may be more challenging when the person with dementia has reduced insight, agitation and resistance to care (Farina et al., 2017). Negative consequences for carers related to the provision of functional care are widely reported and include carer burden, psychological distress, anxiety, depression and poor quality of life (QOL) (Abdollahpour, Noroozian, Nedjat, \& Majdzadeh, 2012; Abreu, Tolson, Jackson, \& Costa, 2018; Farina et al., 2017; Kang et al., 2014; Svendsboe et al., 2016). Moreover, the lack of knowledge, skills and training is a significant challenge faced by family carers when related to functional care (Cova et al., 2018; DiZazzo-Miller, Samuel, Barnas, \& Welker, 2014). As a result, carers can have low confidence in the provision of care (Jennings et al., 2015). To date, there are limited studies that assess carers' needs related to the provision of functional care, in particular, BADLs, for example, carers being uninformed on feeding and nutrition-related care, toileting needs, incontinence and skin care (Ball et al., 2015; Bliss et al., 2013; Mullins, Bliss, Rolnick, Henre, \& Jackson, 2016). Therefore, an exploration of carers' needs related to managing ADLs, particularly the barriers and challenges, and information needs, may be useful in the development of education programs and resources via mobile health solutions. 
The role of modern mobile technology in healthcare is significant. Mobile health (mHealth) is defined as "medical and public health practice supported by mobile devices, such as mobile telephones, patient monitoring devices, personal digital assistants, and other wireless devices" (World Health Organization, 2011, p. 6). Kotz, Gunter, Kumar, and Weiner (2016) claim that these technologies have the potential to enhance the quality of healthcare, expand access to services, decrease costs, and enhance personal wellness and public health. Smartphone applications (apps), also called mHealth apps are a recent innovation in mobile technology and are widely used in health. These mHealth apps are emerging as a costeffective means to provide healthcare information that is readily accessible through mobile communication technologies (Handel, 2011). These apps can provide further individualised health care and education at users' convenience (Boulos, Brewer, Karimkhani, Buller, \& Dellavalle, 2014; Santoro, Castelnuovo, Zoppis, Mauri, \& Sicurello, 2015). Moreover, the use of mHealth apps is a practical method to provide education for widely dispersed groups such as family carers because any person from urban, rural or remote areas can access mHealth apps. In a systematic review, Martínez-Pérez, Torre-Díez, and López-Coronado (2013) state that there are more than 3673 mHealth apps related to the most prevalent health conditions. These apps are increasingly used in different health fields including medical practice, health promotion, medical and nursing education, as well as mental health and chronic disease management (Rathnayake, Moyle, Jones, \& Calleja, 2018), and these are readily accepted by the general public (Kayyali et al., 2017). However, a recent literature review reported that mHealth apps are not widely used among carers of people with dementia, but they are used in carer education, monitoring and cognitive training (Rathnayake et al., 2018). For example, Brown et al. (2016) developed an mHealth app to deliver education concerning providing care for people with dementia and to improve wellness of carers. Reyes, Camargo, and Díaz (2016) developed an mHealth app for carers 
that includes a system for supporting non-pharmacological interventions such as reminiscence therapy, reality orientation therapy, psychosocial therapy and cognitive rehabilitation therapy. Although mHealth apps are yet to be widely used amongst carers of people with dementia, these apps may present a feasible solution to provide them with functional care information to improve care outcomes (Rathnayake et al., 2018).

Consequently, an exploration of family carers' perception towards mHealth apps, particularly related to obtaining information through these apps, is timely.

\section{Methodology}

\section{Study design}

A qualitative descriptive exploratory study was undertaken as a part of a project that guided the development of an mHealth app to improve functional care for carers of people with dementia. In-depth interviews (in-person or by telephone) were conducted with the family carers of people with dementia living in the community in Australia.

\section{Participants}

A purposive sample of ten family carers living in the community in Australia, was recruited to ensure the inclusion of child and spousal carers as well as those providing care for family members at varying stages of dementia. The sample size is deemed appropriate for the nature of this study according to Guest, Bunce and Johnson (2006) in identifying basic themes. The family carers were unpaid primary carers who were aged 18 years and older and provided informal care at home for a person diagnosed with dementia. Carers who selfreported as experiencing major psychiatric disorders (e.g. major depression and schizophrenia) were excluded to avoid additional burden. Carers who had difficulty communicating in English were also excluded. 
Potential carers who expressed their willingness to participate in interviews were recruited from a previously conducted online survey about functional care. An invitation email with an information sheet including study aims and objectives was sent to carers who expressed an interest in being interviewed, and a mutually suitable interview time was arranged.

\section{Data collection}

Data collection was undertaken from February 2018 to April 2018 using a semistructured interview guide (see Table 1). Nine carers participated in telephone interviews, and one carer participated in a face-to-face interview. All participants completed a demographic data sheet prior to the interviews that were conducted by the first author (A1 - blinded for review) in a private office at (blinded for review) University. Interview questions were developed around the study aims and available literature. They consisted of open-ended questions related to carers' experiences of the management of functional disabilities of people with dementia and the use of mHealth apps in health information seeking. The interview guide was pre-tested among three individuals from the general population to test its readability and understandability. The average duration of the interviews was 43 minutes and ranged from 32 minutes to 73 minutes. This varying length of interview times resulted because some participants had more to explore on their needs and experiences related to interview items while others were limited in their responses. Furthermore, some participants spoke quickly while others were much slower with their responses. All interviews were digitally-recorded after consent was obtained from the participants.

This article is protected by copyright. All rights reserved. 


\section{Ethical consideration}

The study was approved by the (blinded for review) Human Research Ethics

Committee (Reference Number: 2017/947). Verbal and written consent was obtained for telephone and face-to-face interviews respectively. Digital recordings of the interviews were deleted after transcription of the data.

\section{Data analysis}

Digital files were transcribed verbatim. Transcripts were compared with the original digital files for accuracy, and all personal identifiers were removed from the transcripts. The participants did not receive transcripts for member checking but received a lay summary of the findings. Inductive thematic analysis, according to the six steps stated by Braun and Clarke (2006), was used. The six steps followed were: (1) familiarisation of the data by reading and re-reading and noting down initial ideas; (2) initial coding in a systematic way across the entire data set; (3) recognising themes by grouping all data relevant to potential theme; (4) reviewing themes leading to the generation of a thematic map; (5) defining and naming of themes by giving clear definitions and names for the themes, and (6) producing a scholarly report based on the analysis.

Following the reading and familiarisation of the transcripts, two authors (A1 \& A3 blinded for review) conducted the initial coding for the first three transcripts. Consensus for elements disagreed on was reached with a third author (A2 - blinded for review). Based on these codes, A1 (blinded for review) completed the initial coding for the whole data set. When new codes were identified, these codes were discussed with other authors (A2 \& A3 blinded for review). Data were then grouped into themes by two authors (A1 and A2 blinded for review), which were then discussed and confirmed by the other authors (A3 \& A4

This article is protected by copyright. All rights reserved. 
- blinded for review). The discussion continued among the authors until consensus was reached and the final themes emerged. The consolidated criteria for reporting qualitative research (COREQ) check list (Tong, Sainsbury \& Craig, 2007) was followed in the reporting of this study (See Supplementary File 1).

\section{Results}

\section{Participant characteristics}

The demographics of interviewed carers are shown in Table 2. The majority of the carers were females $(\mathrm{n}=9)$, and the mean age was 59.4 years $(S D=11.4)$. The sample consisted of five child carers and five spousal carers who were caring for three care recipients in the early stage of dementia, five in the middle stage and two in the later stage.

\section{Findings}

Four key themes emerged from the interviews (see Table 3). These themes are discussed and supported by exemplary quotations extracted from the transcripts. Carers were de-identified using a participant number (e.g. P1) in the reporting.

\section{Theme one: Challenges faced that contribute to psychological distress and burden}

This theme highlights the barriers and challenges concerning the management of functional care. The most difficult activities reported by carers were bathing, toileting, dressing, transferring and feeding (i.e. BADLs) as well as medication management and shopping or going on a small trip (i.e. IADLs). The majority of challenges and barriers are related to factors associated with the signs and symptoms of the care recipients' condition. One of the main barriers for providing care for ADLs was the complexity of the condition, particularly continuing changes in the symptoms and the need to consider different management strategies. One carer stated that the second episode is rarely the same as the first 
episode. 'It's funny what works and what doesn't. What works this time may not work next time? It's a continuation of trying something different pretty much every time because very rarely is there a second episode that's the same as the first" (P2). Carers also reported that aggressive and agitative behaviours impeded organisation of functional care while wandering and distractive behaviour made it difficult to go shopping, run simple errands or go on a trip. "You couldn't take him out anywhere because he'd get very upset if you tried to guide him in a crowd, and he would become very volatile, very loud about what was going on, how people would be in his way. It was difficult” (P7).

Other significant challenges faced by carers were memory impairment, resistance to care and communication difficulties. Carers reported that memory impairment leads to reduced recognition of carers, and hinders a productive relationship with care recipients. Poor orientation to date and time also leads to difficulties with the organisation of care. "He doesn't know; he's always asking what day it is. Everything is written on the calendar. He understands the work. He just gets confused with days" (P5). Care recipients are reported to have forgotten how to complete daily living tasks; therefore, carers have to remind them how to undertake routine tasks and spend more time supervising those activities that now take more time to complete. "I think it's the repetitive nature of cleaning teeth. Mum forgets what she's doing at the time, so she just keeps cleaning. So, it just takes hours" (P1). Carers further highlighted that memory impairment leads to difficulties in medication management and the lack of understanding and recognition of money leads to difficulty in handling finance and shopping.

Care recipients may be resistant to or completely reject care, including showing a lack of interest and reduced engagement in self-care activities. Although they have difficulties in meeting their functional needs, they seek independence in completing those activities which can lead to other challenges. One carer stated that her father was at high risk of falling, but he 
wanted to maintain independence. He would not allow her to provide care for him and as a result, he suffered a fall. "...he's like. 'I can manage it; I can manage it' and then it was too late when he was falling over..."(P4).

Communication difficulties were identified as a significant barrier to supporting ADLs and carers reported this hinders the effective coordination of care. "I think it was very difficult in so many areas because he found it difficult to understand what you were trying to tell him. Sometime I could speak to him, and he would not hear or reply to me" (P7). When current communication methods fail, introducing a new communication method was challenging as it is a difficult for people with dementia to learn new communication skills. One carer reported that when the idea of using a bell was introduced to her mother, she took a long time to learn how to ring a bell for attention. Carers also said that an inability to use the telephone increased care needs, especially in care coordination. "He did not use the telephone, so I would actually have to have the care workers ring me, and then I would have to go and tell him what time they were coming" (P4).

The presence of co-morbidities and related health problems of care recipients creates a complex care situation, particularly in the provision of BADLs. Family carers reported that fatigue and physical weaknesses of care recipients affect their independence in daily living. "He doesn't need any physical help with toileting or bathing. With his physical condition, weakness, he's very, very slow. It takes more time to complete the works" (P5). The risk of aspiration due to dysphagia, inadequate fluid intake, the risk of falls and fractures, infections, arthritis, incontinence and constipation were the other main problems reported by carers that increased difficulties in supporting functional care.

Most family carers stated that giving functional disability care leads to distress, in particular where there is a role reversal of carers. The loss of dignity and privacy of care recipients during self-care, especially in toileting and bathing, increased the emotional 
distress of carers. "It's like having another child basically, but you need to act in a respectful manner because it's your mum, but it's difficult to do that caring role when it is your mum" (P10). Most family carers reported fatigue concerning support for ADLs, especially in selfcare activities. The dependency of care recipients and their high demand for care and support lead to an elevated physical toll on carers. "At the end of the day, I am tired, very tired. I have no physical energy to work for him" (P3) and this adversely impacted on their quality of life.

\section{Theme 2: Essential role of support systems in dementia care}

This theme discusses positive and negative support systems available for carers for the provision of functional care. Family carers indicated that support from other family members, government, direct care organisations within the community and peers play a significant role in their provision of functional care. They emphasised that family support creates a positive caring environment, primarily where this support system provides a break or respite for the primary carer. However, a lack of family support was reported. "Well, I don't have any support from the family. One lives here, one lives in Brisbane, and one lives in Canberra. The other thing, the daughter here, she feels I should put him in a home, that's all. Other than that, they don't interfere or participate" (P9). Nevertheless, where there were many family members involved in the care, this often helped the situation. "I am lucky that I can be home for a lot of days. I have two brothers who live close here, and they can pop in once a week or something" (P10).

Carers further addressed supportive mechanisms available from the government, for example, carer payments, pensions and support from the department of veteran affairs (DVA). One carer stated that DVA supported them to access services without financial burden. "My mum is with DVA, and so in terms of availability of resources, we had no worries, no problems because DVA is really good with funding things" (P1). However, most 
carers reported that direct support received from the government was inadequate. "I don't believe the Government gives a great deal of care. I live in a rural area, and up until the middle of last year, my husband was the only patient in this area with Alzheimer's. There's no support here. Our support comes from 50 kilometres away" (P3).

Generally, family carers held positive attitudes towards direct care organisations available in the community that provide respite care, day care, home care and paid carer support services. They reported that such services helped them to take a break, and reduced their distress and burden. "I had staff who would come and relieve me for three hours so I could go and have a sleep" (P4). However, they highlighted that arranging those services is somewhat challenging due to untimely communication with the paid care workers and care organisations "What difficulties going through that My Age Care. I was going away for ten days, and I wanted to organise the social visits. The people didn't get back to me in time. The morning we were leaving for our holiday, at lunchtime, that's when they came and did the paper work to organise the social visit" (P8).

Family carers highlighted carer support groups as an essential support mechanism in the community. "I do believe there are fantastic groups out there that do give the carer support. Carers Online is one" (P3). They stated that these support groups are beneficial in sharing experiences, particularly care tips. Most carers said that they are in Facebook groups for dementia carers and highlighted that these platforms help to share experiences, obtain information or to learn caregiving tips and provide emotional support. "I found a Facebook page about carers, and I joined that. People are very supportive ... so I feel like that could be the support system ...the Facebook page, it's more emotional support..." (P8).

This article is protected by copyright. All rights reserved. 


\section{Theme 3: Information and educational needs of family carers}

This theme encapsulates the information and educational needs of carers. Family carers highly valued the available information sources and opportunities for education. The primary information sources highlighted were support staff, training programs, online resources, websites and printed materials. However, carers viewed the lack of personal knowledge and skills as a challenge when giving functional care. They said that available information was not adequate, may not be applicable or relevant to their care needs, and improvements are required. They further reported difficulties in finding relevant and credible information. "It is hard to get relevant information, and I'll get three out of those that help. You can go round and round” (P9).

Information and support fragmentation was another issue reported by carers. One carer said that sources of information or support may at times only provide content or assistance relevant to one problem or a part of care. Consequently, they had to go to several places to receive information or support, and this process was frustrating. "You go to this person, and you'll say, 'okay', this like, 'oh yeah, we can help you with this part of it, but then you have to go to the next person, and then they say to you, 'oh yeah, but we don't do that anymore" (P7). They also highlighted that most online sources and print materials did not cover all areas. Additionally, carers reported inadequate skills in using technology to access online sources as well as limited available time to search for information and participate in educational programs.

The primary support workers who provided educational support, particularly in managing ADLs included nurses, occupational therapists, incontinence nurses, general practitioners and paid carers. Although they provide information and education, family carers stated that sometimes these were inadequate in meeting their care needs. One carer stated that health workers did not explain health records and investigations adequately. Carers 
highlighted difficulties in obtaining information from care staff; for example, in relation to respite care, due to healthcare staff's busy workload.

\section{Theme 4: Experiences and attitudes of mHealth applications as an educational and supportive resource}

This theme relates to individual experiences and attitudes towards mHealth apps of carers of people with dementia. Most family carers had a positive attitude toward mHealth apps and perceived it could be a viable option for them to access health information related to functional care. "Apps would be beneficial for carers to know what's new, what's out there, what happens and to maintain the currency of information, tools and services" (p10). They further highlighted that mHealth apps can be time effective in providing support and information, all in one place. "I don't get a lot of time, but when you are looking, you'd like just to be able to go straight to it...to find what you're looking for, all right and, timesaving."' (P3).

Nevertheless, carers highlighted several barriers and challenges related to using mHealth apps. The need for a smartphone or tablet as well as internet facilities or mobile data are cost related barriers highlighted by carers. There were reported concerns about the memory capacity of their smartphone in running apps and their potential in reducing phone processing speed and battery life. Carers further stressed that technology would be a challenge, especially for older carers, as mHealth apps demand specific technical skills. For example, one carer highlighted that she had to ask for help from her husband to organise the apps on her phone. Whereas these carers highlighted that they have limited time for using mHealth apps with their caring role. "I don't spend a lot of time on my phone or device. The only time I get is when the husband is at respite and generally I have to spend that time catching up on work that needs to be done" (P3). Additionally, they stated that health 
conditions of carers (e.g. poor vision), the awareness of available mHealth apps and information seeking patterns might hinder the use of apps. Nevertheless, given the growing popularity and use of smartphones and tablets, including apps, carers acknowledged the need to have mHealth apps designed for carers of people with dementia. "The generation that's coming up now, on the phone all the time. They really know how to use a phone" (P9).

Family carers highlighted that mHealth apps need to be simple; navigation needs to be user-friendly; and able to provide quick access to information. "If you've got something, sort of a concern, it's better off to be able to just quickly open an app, and find the information you need as opposed to searching through something like Google" (P6). Features of mHealth apps suggested by carers that might be useful were comprised of sending reminders to take medications; sending alert/caring tips to encourage carers; calendar and appointment arrangements; and leisure activities such as the delivery of music. Finally, carers proposed that the mHealth apps should include content in the following areas: information on dementia including types, progression and management; information related to managing ADLs and aggressive behaviours; information on available services, facilities, information sources, training opportunities and equipment; as well as information and strategies for looking after carers' health and well-being.

\section{Discussion}

This study provides insights into the needs, barriers and challenges faced by family carers of people with dementia concerning the management of functional disability of their care recipients and their perceptions of using mHealth apps in health information seeking. To our knowledge, this is the first reported qualitative inquiry that provides insights into these areas related to functional care that guides the development of an mHealth app. 


\section{Carer burden related to functional care}

Carer burden is a significant issue amongst carers of people with dementia. In line with previous studies, this study confirmed that providing functional care is demanding, challenging and stressful (Abdollahpour et al., 2012; Kang et al., 2014; Svendsboe et al., 2016). Increased functional limitations of people with dementia were associated with the development of fatigue among carers (Osaki et al., 2016). The issue of fatigue is further exacerbated by the lack of time for leisure activities (Osaki et al., 2016) and carers in our study reported that they had no time for rest or leisure activities. Hirano et al. (2010) reported that leisure activities were inversely associated with the care burden of dementia. Carer burden leads to poor health status and reduced quality of life for carers (Farina et al., 2017; Svendsboe et al., 2016). Consequently, educational and support programs can provide strategies to assist family carers in managing distress and burden experienced during ADL care provision.

\section{Challenges and barriers faced by carers related to providing functional care}

In this study, the different challenges and barriers leading to family carers' distress and burden were found to be related to functional care where it was impeded by the complex nature of dementia including memory impairment, resistance to care and communication difficulties. Management of ADLs in people with dementia is also reported in the literature as a contributing factor to carer burden (Chan et al. 2010; Yu, Wang, He, Liang, and Zhou, 2015). The changing nature of dementia symptoms is a significant barrier in care planning and organisation due to a decline in memory and executive function leading to social and occupational impairments in people with dementia (Abreu et al, 2018; Tarawneh \& Holtzman, 2012). 
Resistance to care is another significant barrier to the provision of functional care. This is a common problem of people with dementia who are dependent and have severe cognitive impairment, and resistance to care increases when their ability to understand conversation deteriorates (Volicer, Bass, \& Luther, 2007). In this study, difficulties in communication as a result of dementia challenged carers in providing functional care. In general, memory and language decline cause the development of communication difficulties among people with dementia (Wilson, Rochon, Leonard, \& Mihailidis, 2012a) and these problems negatively affect the carer-care recipient relationship, leading to increased time spent on functional care, and increased carer stress and burden (Wilson, Rochon, Mihailidis, \& Leonarda, 2012b). Therefore, the use of appropriate communication mechanisms is an essential strategy in providing successful functional care (Wilson et al., 2012a).

Carers' stress related to role reversal found in this study coincides with the findings of a previous study (Samuelsson, Annerstedt, Elmståhl, Samuelsson, \& Grafström, 2001). They found that husbands, taking on the caregiving role for their wives living with dementia, reported worry, weariness, guilt, distress and isolation. Often carers have to move from the role of a spouse, child, sibling or friend to the role of 'carer'. Taking new responsibilities leads to an imbalance in previous relationships and the assistance received from each other (Llanque, Savage, Rosenburg, \& Caserta, 2016). They have to provide unpaid care for their care recipients at the same time managing their own health, finance, and work (Brodaty \& Donkin, 2009). Consequently, it appears that cognitive changes including memory impairment, communication difficulties and resistance to care as well as problems related to role reversal, are the critical barriers to providing functional care.

From the view of the carers in our study, various health problems of people with dementia increase the needs and complexity of functional care. Physical weakness and fatigue were a significant barrier in assisting with tasks such as bathing, dressing and 
toileting. Other health issues that complicated functional care provision included dysphagia, falls and fractures, infections, arthritis, incontinence and constipation. These health problems and co-morbidities are highly prevalent among people with dementia, and aggravate the progression of dementia and increase the particular challenges of care (Bunn et al., 2014).

Consequently, care support services and providers as well as health professionals need to take into consideration the challenges and barriers faced by carers related to providing functional care when planning strategies to support family carers.

\section{Role of the support system in providing functional care}

Our study found that support systems available within the community, for example, family support, government support, direct support services available within the community, and peer support groups including social media groups, have an essential role in familycentred dementia care. Health care professionals are the key personnel in addressing the emotional, practical and informational needs of family carers (Ekstedt, Stenberg, Olsson, \& Ruland, 2014). While carers in our study do value the support received from the healthcare professionals, they felt that it was neither adequate nor timely. Formal community care services (e.g. respite care, day care, home care and paid carer support services) are essential mechanisms in community dementia care. However, inadequate support services remain a significant problem in the community dementia care (Parkinson et al., 2017), and the availability of such facilities is limited or finding suitable services is difficult (Robinson et al., 2009). Carers in our study also expressed these issues. The lack of awareness about available support services within the community is another barrier to access those services (DiZazzo-Miller, Pociask, \& Samuel, 2013). Therefore, it is essential to increase carers' awareness about available supportive services. Alternative support systems are required. Peer support including social media groups reduces social isolation, stress and risk of depression 
as well as improves informational and emotional support, self-efficacy, a sense of support and psychological well-being of carers (Bateman et al., 2017; Parkinson et al., 2017). Consequently, the establishment of care-networks within the community for carers is imperative. Further in-depth understanding of the contribution of social media groups in dementia care support for family carers is needed. Although carers in Australia receive several services and support including education, training, case management approaches, psychosocial help, support from social groups and respite care services (Alzheimer's Australia, 2015), this study demonstrates the inadequacy of support systems for carers as a problem. Carers viewed that the government needs to improve direct support, particularly welfare facilities.

\section{Educational and information needs of carers}

Family carers reported inadequate knowledge and skills towards providing functional care, and this is in line with previous literature (Cova et al., 2018; DiZazzo-Miller et al., 2014; Jennings et al., 2015). A recent literature review identified the needs associated with functional care as one of the main types of information and knowledge needs of carers of people with dementia (McCabe et al., 2016). Similar to our study, carers have previously indicated that they received inadequate information and faced difficulties in finding credible and reliable information (Peterson, Hahn, Lee, Madison, \& Atri, 2016). Health literacy and eHealth literacy are essential skills for finding credible and reliable information (Keleher \& Hagger, 2007; Norman \& Skinner, 2006). Therefore, health professionals have a significant role in educating carers by providing accurate information and direction in finding credible and reliable sources.

This article is protected by copyright. All rights reserved. 
Carers in our study highly regarded the role of health professionals in providing information. However, they reported some challenges in communicating with healthcare professionals. Recent studies have also reported ineffective communication between health professionals and informal carers of people with dementia (Caswell, Pollock, Harwood, \& Porock, 2015; Peterson et al., 2016). This is, in part, due to health professionals having a poor understanding of the problems experienced by carers and therefore, simply disregarding their problems (Manthorpe et al.,2013). Consequently, not only do health professionals need to understand and address problems faced by carers, they also need to apply effective communication strategies when providing education to carers.

\section{mHealth application as an educational and supportive resource}

Today, mHealth apps are widely used in healthcare. In our study, family carers had positive attitudes towards mHealth apps. They identified mHealth apps as a supportive intervention to address information and education needs related to functional care, mainly to obtain timely health information. This is likely to be the result of information on mHealth apps being easily accessible online (Handel, 2011), and providing real-time, demand-driven communication (Boulos et al, 2014). In our study, carers further identified mHealth apps as a platform to obtain time effective support and information, all in one place. Today, mobile devices where apps are used are becoming smaller, lighter, and less expensive (Wang \& Liu, 2009). Literature indicates that mHealth apps can provide personalised support and education at a convenient time (Boulos et al, 2014; Santoro et al, 2015). Therefore, mHealth app interventions may help address the knowledge needed by carers to support functional care given to people with dementia.

This article is protected by copyright. All rights reserved. 
Family carers identified time limitations, cost and technology as significant barriers to their use of mHealth apps and this is congruent with other study findings about mHealth apps for family carers (Rathnayke et al., 2018; Williamson, Gorman, \& Jimison, 2014). However, the use of mHealth apps can minimise some challenges in traditional educational methods, for example, affordability due to high cost and accessibility due to transportation, time and location (Davis, Shehab, Shenk, \& Nies, 2015). Recent reviews reported that these apps were effective in health education and support (Kitsiou, Paré, Jaana, \& Gerber, 2017; Xiong et al., 2018). Despite the reported limitations, mHealth apps offer the opportunity to be a feasible education and support resource for family carers of people with dementia to address knowledge needs related to functional care.

\section{Limitations}

Findings of this study are limited by the small sample of carers and it is likely that people who were health literate are more likely to have responded. Therefore, the findings of the study may not be fully reflective of the wider carer population. Additionally, we did not examine the influence of socio-demographic factors; therefore, future studies are needed to explore the influence of factors such as gender, socio-economic status, culture or ethnicity in functional care needs and the use of mHealth apps.

\section{Conclusion}

Results of this study provide insights into the needs, barriers and challenges concerning functional care and the use of mHealth apps of carers of people with dementia living in Australia. Family carers of people with dementia present with care burden as a result of the provision of functional care. The complexity of the dementia syndrome including memory impairment, the changing nature of symptoms and communication difficulties is one 
of the most significant barriers in providing functional care. Access to a support network is vital to provision of functional care. Inadequate knowledge and skills to providing functional care is a significant challenge. Finding credible and reliable information, information and support fragmentation together with insufficient information received from healthcare professionals were some of the issues highlighted by carers in information seeking. mHealth apps appear to offer an opportunity for family carers to use to improve their knowledge and therefore to provide support with attention placed on end users' health literacy levels when designing these educational mHealth app interventions. Further research is needed that compares mHealth apps with the other usual forms of support identified by the carers in this study.

\section{Relevance to clinical practice}

This study provides an insight into the needs, barriers and challenges of family carers concerning functional care for recipients with dementia. Findings from this study will help nurses and community care workers to plan and organise functional care education and support for carers of people with dementia living in the community. Our study findings highlight the need for nurses, healthcare professionals and agencies as well as the government to review the adequacy of their existing support systems and where necessary, to address the needs of family carers of people with dementia to reduce the need for long-term institutionalisation and unnecessary hospital admission. Community healthcare nurses can also monitor and support carers of people with dementia as carer distress and burden is a common issue related to the challenges of functional care. The findings of this study support the use of mHealth apps in education and support for family carers of dementia. As indicated in our study, finding credible and reliable information is a difficult task for carers; therefore, community health nurses and other care professionals can help their clients to locate credible 
data sources. Last but not least, findings from our study can assist app developers, clinicians and researchers to develop mHealth app-based interventions for family carers of people with dementia.

\section{References}

Abdollahpour, I., Noroozian, M., Nedjat, S., \& Majdzadeh, R. (2012). Caregiver burden and its determinants among the family members of patients with dementia. International Journal of Preventive Medicine, 3(8), 544-551.

Abreu, W., Tolson, D., Jackson, G. A., \& Costa, N. (2018). A cross-sectional study of family caregiver burden and psychological distress linked to frailty and functional dependency of a relative with advanced dementia. Dementia, 0(0), 1-18. doi:10.1177/1471301218773842

Alzheimer's Australia. (2015). Caring for someone with dementia: The economic, social, and health impacts of caring and evidence based support for carers. Retrieved from https://www.dementia.org.au/files/NATIONAL/documents/Alzheimers-AustraliaNumbered-Publication-42.pdf

Australia Institute of Health and Welfare. (2012). Dementia in Australia. Cat. no. AGE 70. Retrieved from http://www.aihw.gov.au/WorkArea/DownloadAsset.aspx?id=10737422943.

Ball, L., Jansen, S., Desbrow, B., Morgan, K., Moyle, W., \& Hughes, R. (2015). Experiences and nutrition support strategies in dementia care: Lessons from family carers. Nutrition \& Dietetics, 72(1), 22-29. doi: 10.1111/1747-0080.12107.

Bamm, E. L., \& Rosenbaum, P. (2008). Family-centered theory: Origins, development, barriers, and supports to implementation in rehabilitation medicine. Archives of 
physical medicine and rehabilitation, 89(8), 1618-1624.

doi:10.1016/j.apmr.2007.12.034.

Bateman, D. R., Brady, E., Wilkerson, D., Yi, E.-H., Karanam, Y., \& Callahan, C. M. (2017). Comparing crowdsourcing and friendsourcing: A social media-based feasibility study to support Alzheimer disease caregivers. JMIR Research Protocols, 6(4), e56. doi: 10.2196/resprot.6904.

Bliss, D., Rolnick, C., Jackson, J., Arntson, C., Mullins, J., \& Hepburn, K. (2013). Health literacy needs related to incontinence and skin damage among family and friend caregivers of individuals with dementia. Journal of Wound, Ostomy, and Continence Nursing: Official Publication of The Wound, Ostomy and Continence Nurses Society/WOCN, 40(5), 515. doi:10.1097/WON.0b013e3182a3ff24

Boulos, M. N. K., Brewer, A. C., Karimkhani, C., Buller, D. B., \& Dellavalle, R. P. (2014). Mobile medical and health apps: State of the art, concerns, regulatory control and certification. Online Journal of Public Health Informatics, 5(3), 229. doi: 10.5210/ojphi.v5i3.4814

Braun, V., \& Clarke, V. (2006). Using thematic analysis in psychology. Qualitative Research in Psychology, 3(2), 77-101. doi.org/10.1191/1478088706qp063oa

Brodaty, H., \& Donkin, M. (2009). Family caregivers of PWD. Dialogues in Clinical Neuroscience, 11(2), 217-228.

Brown, E. L., Ruggiano, N., Page, T. F., Roberts, L., Hristidis, V., Whiteman, K. L., \& Castro, J. (2016). CareHeroes Web and Android ${ }^{\mathrm{TM}}$ Apps for Dementia Caregivers. Research in Gerontological Nursing, 9(4), 193-203. doi:10.3928/1940492120160229-02

This article is protected by copyright. All rights reserved. 
Bunn, F., Burn, A., Goodman, C., Rait, G., Norton, S., Robinson, L., . . Brayne, C. (2014). Comorbidity and dementia: A scoping review of the literature. BMC Medicine, 12(1). doi:10.1186/s12916-014-0192-4

Cabote, C. J., Bramble, M., \& McCann, D. (2015). Family caregivers' experiences of caring for a relative with younger onset dementia: A qualitative systematic review. Journal of Family Nursing, 21(3), 443-468. doi: 10.1177/1074840715573870

Caswell, G., Pollock, K., Harwood, R., \& Porock, D. (2015). Communication between family carers and health professionals about end-of-life care for older people in the acute hospital setting: A qualitative study. BMC Palliat Care, 14(1), 35. doi:10.1186/s12904-015-0032-0

Chan, W.C., Ng, C., Mok, C. C., Wong, F. L.F., Pang, S.L., \& Chiu, H. F.K. (2010). Lived experience of caregivers of persons with dementia in Hong Kong: A qualitative study. East Asian Archives of Psychiatry, 20(4), 163-168.

Cova, I., Travi, N., Maggiore, L., Cucumo, V., Mariani, C., \& Pomati, S. (2018). What are the caregivers' needs on dementia care? An integrated qualitative and quantitative assessment. Neurological Sciences, 39(6), 1085-1091. doi.org/10.1007/s10072-018$3332-3$

Davis, B. H., Shehab, M., Shenk, D., \& Nies, M. (2015). E-mobile pilot for community-based dementia caregivers identifies desire for security. Gerontechnology, 13(3), 332-336. oi:10.4017/ gt.2015.13.3.003.00

DiZazzo-Miller, R., Pociask, F. D., \& Samuel, P. (2013). Understanding resource needs of persons with dementia and their caregivers. Michigan Family Review, 17(1)1-20. doi.org/10.3998/mfr.4919087.0017.102

DiZazzo-Miller, R., Samuel, P. S., Barnas, J. M., \& Welker, K. M. (2014). Addressing everyday challenges: Feasibility of a family caregiver training program for PWD. 
American Journal of Occupational Therapy, 68(2), 212-220.

doi.org/10.5014/ajot.2014.009829

Ekstedt, M., Stenberg, U., Olsson, M., \& Ruland, C. M. (2014). Health care professionals' perspectives of the experiences of family caregivers during in-patient cancer care. Journal of Family Nursing, 20(4), 462-486. doi: 10.1177/1074840714556179

Farina, N., Page, T. E., Daley, S., Brown, A., Bowling, A., Basset, T., . . Banerjee, S. (2017). Factors associated with the quality of life of family carers of people with dementia: A systematic review. Alzheimer's \& Dementia, 13(5), 572-581. doi: http://dx.doi.org/10.1016/j.jalz.2016.12.010

Guest, G., Bunce, A., \& Johnson, L. (2006). How many interviews are enough? An experiment with data saturation and variability. Field Methods, 18(1), 59-82. doi: $10.1177 / 1525822 X 05279903$

Handel, M. J. (2011). mHealth (Mobile Health): Using apps for health and wellness. Explore, 7, 256-262. doi.org/10.1016/j.explore.2011.04.011.

Hirano, A., Suzuki, Y., Kuzuya, M., Onishi, J., Hasegawa, J., Ban, N., \& Umegaki, H. (2010). Association between the caregiver's burden and physical activity in community-dwelling caregivers of dementia patients. Archives of Gerontology and Geriatrics, 52(3), 295-298. doi:10.1016/j.archger.2010.04.011.

Jennings, L. A., Reuben, D. B., Evertson, L. C., Serrano, K. S., Ercoli, L., Grill, J., . . . Wenger, N. S. (2015). Unmet needs of caregivers of individuals referred to a Dementia Care Program. Journal of the American Geriatrics Society, 63(2), 282-289. doi:10.1111/jgs.13251

Kang, H. S., Myung, W., Na, D. L., Kim, S. Y., Lee, J. H., Han, S. H., . . Kim, D. K. (2014). Factors associated with caregiver burden in patients with Alzheimer's disease. Psychiatry Investigation, 11(2), 152-159. doi:10.4306/pi.2014.11.2.152

This article is protected by copyright. All rights reserved. 
Kayyali, R., Peletidi, A., Ismail, M., Hashim, Z., Bandeira, P., Bonnah, J., . . Aliki, P. (2017). Awareness and use of mHealth apps: A study from England. Pharmacy (Basel, Switzerland), 5(2), 33. doi:10.3390/pharmacy5020033

Keleher, H., \& Hagger, V. (2007). Health literacy in primary health care. Australian Journal of Primary Health, 13(2), 24-30. doi: 10.1071/PY07020

Kitsiou, S., Paré, G., Jaana, M., \& Gerber, B. (2017). Effectiveness of mHealth interventions for patients with diabetes: An overview of systematic reviews. PLOS ONE, 12(3), e0173160. doi:10.1371/ journal.pone.0173160.

Kotz, D., Gunter, C. A., Kumar, S., \& Weiner, J. P. (2016). Privacy and Security in Mobile Health: A Research Agenda. Computer, 49(6), 22-30. doi:10.1109/MC.2016.185

Llanque, S., Savage, L., Rosenburg, N., \& Caserta, M. (2016). Concept Analysis: Alzheimer's Caregiver Stress. Nursing Forum, 51(1), 21-31. doi:10.1111/nuf.12090.

Manthorpe, J., Samsi, K., Campbell, S., Abley, C., Keady, J., Bond, J., . . Iliffe, S. (2013). From forgetfulness to dementia: clinical and commissioning implications of diagnostic experiences. British Journal of General Practice, 63(606), e69-e75. doi: 10.3399/bjgp13X660805.

Martínez-Pérez, B., Torre-Díez, I. D. L., \& López-Coronado, M. (2013). Mobile health applications for the most prevalent conditions by the World Health Organization: review and analysis. Journal of medical Internet research, 15(6), e120. doi:10.2196/jmir.2600

McCabe, M., You, E., \& Tatangelo, G. (2016). Hearing Their Voice: A Systematic Review of Dementia Family Caregivers' Needs. Gerontologist, 56(5), e70-e88. doi:10.1093/geront/gnw078.

This article is protected by copyright. All rights reserved. 
Mlinac, M. E., \& Feng, M. C. (2016). Assessment of activities of daily living, self-care, and independence. Archives of Clinical Neuropsychology, 31(2016), 506-516. doi:10.1093/arclin/acw049

Mullins, J., Bliss, D. Z., Rolnick, S., Henre, C. A., \& Jackson, J. (2016). Barriers to communication with a healthcare provider and health literacy about incontinence among informal caregivers of individuals with dementia. Journal of Wound, Ostomy, and Continence Nursing: Official Publication of The Wound, Ostomy and Continence Nurses' Society/WOCN, 43(5), 539 -544. doi: 10.1097/WON.0000000000000263.

Norman, C. D., \& Skinner, H. A. (2006). eHealth Literacy: Essential skills for consumer health in a networked world. Journal of Medical Internet Research, 8(2), e9. doi:10.2196/jmir.8.2.e9

Osaki, T., Morikawa, T., Kajita, H., Kobayashi, N., Kondo, K., \& Maeda, K. (2016). Caregiver burden and fatigue in caregivers of people with dementia: Measuring human herpesvirus (HHV)-6 and -7 DNA levels in saliva. Archives of Gerontology and Geriatrics, 66, 42-48. doi:10.1016/j.archger.2016.04.015

Parkinson, M., Carr, S. M., Rushmer, R., \& Abley, C. (2017). Investigating what works to support family carers of people with dementia: A rapid realist review. Journal of Public Health, 39(4), e290-e301. doi:10.1093/pubmed/fdw100

Peterson, K., Hahn, H., Lee, A. J., Madison, C. A., \& Atri, A. (2016). In the information age, do dementia caregivers get the information they need? Semi-structured interviews to determine informal caregivers' education needs, barriers, and preferences. $B M C$ Geriatrics, 16(1), 164. doi:10.1186/s12877-016-0338-7

Rathnayake, S., Moyle, W., Jones, C., \& Calleja, P. (2018). mHealth applications as an educational and supportive resource for family carers of people with dementia: An integrative review. Dementia,. doi:10.1177/1471301218768903

This article is protected by copyright. All rights reserved. 
Reyes, A. K., Camargo, J. E., \& Díaz, G. M. (2016). Design of a mobile application to support non-pharmacological therapies for people with alzheimer disease. In: Vol. 9545. International Conference for Smart Health, ICSH 2015 (pp. 321-332).

Robinson, A., Elder, J., Emden, C., Lea, E., Turner, P., \& Vickers, J. (2009). Information pathways into dementia care services: Family carers have their say. Dementia, $8(1)$, 17-37. doi:10.1177/1471301208099051

Samuelsson, A. M., Annerstedt, L., Elmståhl, S., Samuelsson, S. M., \& Grafström, M. (2001). Burden of responsibility experienced by family caregivers of elderly dementia sufferers: analyses of strain, feelings and coping strategies. Scandinavian Journal of Caring Sciences, 15(1), 25-33. doi: 10.1046/j.1471-6712.2001.1510025.x

Santoro, E., Castelnuovo, G., Zoppis, I., Mauri, G., \& Sicurello, F. (2015). Social media and mobile applications in chronic disease prevention and management. Frontiers in Psychology, 6, 567/. doi: 10.3389/fpsyg.2015.00567

Svendsboe, E., Terum, T., Testad, I., Aarsland, D., Ulstein, I., Corbett, A., \& Rongve, A. (2016). Caregiver burden in family carers of people with dementia with Lewy bodies and Alzheimer's disease. International Journal of Geriatric Psychiatry, 31(9), 10751083. doi:10.1002/gps.4433. doi.10.1093/intqhe/mzm042

Tarawneh, R., \& Holtzman, D. M. (2012). The clinical problem of symptomatic Alzheimer disease and mild cognitive impairment. Cold Spring Harbor Perspectives in Medicine, a006148. doi: 10.1101/cshperspect.a006148.

Tong, A., Sainsbury, P., \& Craig, J. (2007). Consolidated criteria for reporting qualitative research (COREQ): A 32-item checklist for interviews and focus groups. International Journal for Quality in Health Care, 19(6), 349-357. doi:10.1093/intqhe/mzm042 
Volicer, L., Bass, E. A., \& Luther, S. L. (2007). Agitation and resistiveness to care are two separate behavioral syndromes of dementia. Journal of the American Medical Directors Association, 8(8), 527-532. doi.org/10.1016/j.jamda.2007.05.005.

Wang, H., \& Liu, J. (2009). Mobile phone based health care technology. Recent Patents on Biomedical Engineering, 2(1), 15-21.

Williamson, S. S., Gorman, P. N., \& Jimison, H. B. (2014). A mobile/web app for long distance caregivers of older adults: Functional requirements and design implications from a user centered design process. AMIA Annual Symposium Proceedings. 2014, 1960-1969. American Medical Informatics Association.

Wilson, R., Rochon, E., Leonard, C., \& Mihailidis, A. (2012a). Formal caregivers' perceptions of effective communication strategies while assisting residents with Alzheimer's disease during activities of daily living. Canadian Journal of SpeechLanguage Pathology and Audiology, 36(4), 314-331.

Wilson, R., Rochon, E., Mihailidis, A., \& Leonarda, C. (2012b). Examining success of communication strategies used by formal caregivers assisting individuals with Alzheimer's disease during an activity of daily living. Journal of Speech, Language, and Hearing Research, 55(2), 328-341. doi:10.1044/1092-4388(2011/10-0206.

World Health Organization. (2011). mHealth; New horizons for health through mobile technologies. Retrieved from http://www.who.int/mediacentre/factsheets/fs362/en/

Xiong, S., Berkhouse, H., Schooler, M., Pu, W., Sun, A., Gong, E., \& Yan, L. L. (2018). Effectiveness of mHealth interventions in improving medication adherence among people with hypertension: A systematic review. Current Hypertension Reports, 20(10), 86. doi.org/10.1007/s11906-018-0886-7.

This article is protected by copyright. All rights reserved. 
Yu, H., Wang, X., He, R., Liang, R., \& Zhou, L. (2015). Measuring the caregiver burden of caring for community-residing people with Alzheimer's disease. PLoS ONE, 10(7), e0132168. doi:10.1371/journal.pone.0132168

This article is protected by copyright. All rights reserved. 
Table 1: Interview guide

\section{Personal information and background}

- $\quad$ Can you please tell me a little about yourself?

\section{Questions}

- As a family carer, what type of help do you provide in meeting your family member's needs related to their daily activities?

- $\quad$ Could you please tell me what are the activities you find difficult to perform for your family member?

- $\quad$ Could you tell me the difficulties you face in providing support to your family member's needs related to their daily activities? (For example, difficulties with knowledge and skills, and availability of resources etc.)

- What information do you believe you need to know to help you to manage the daily activities of your family member?

- What are the major barriers and challenges you face in getting information to help you care for your family member?

- $\quad$ Do you have any experience with health-related smartphone apps or any other smartphone apps?

- Do you think a smartphone app for carers of people with dementia would be helpful for you to learn about managing the daily activities of your family member?

- What do you see are the advantages of a smartphone app?

- What do you see are the disadvantages of a smartphone app?

- What are the major barriers and challenges you face to access smartphone apps to receive appropriate information to help you in your caregiving role?

- Is there anything else you would like to add to our understanding of managing disabilities of your family member in daily activities and smartphone apps as an educational tool?

- Do you have any questions or further responses?

This article is protected by copyright. All rights reserved. 
Table 2: Participant demographics $(n=10)$

\section{Characteristics}

Carer and care recipients

Age

Below 65 years 80

65 years and older

\section{Gender}

Male

Female

\section{Marital status}

Married

Single

Widowed/divorced

Education

High school and below 50

Above high school

\section{Employment status}

Presently unemployed 40

Presently employed 30

Retired

Carer relationship to the care recipient

Child

Spouse

Duration of caregiving

Less than one year

1-3 years

3-5 years

Above five years

Care recipients' age

Less than 65 years

This article is protected by copyright. All rights reserved. 
65-74 years

75-84 years

85 years and older

40

Care recipients' type of dementia

Alzheimer's disease 50

Frontotemporal dementia 20

Lewy body dementia 20

Early onset dementia 10

Stage of dementia

Early stage 30

Middle stage 50

Late stage 20

This article is protected by copyright. All rights reserved. 
Table 3: Themes and sub-themes

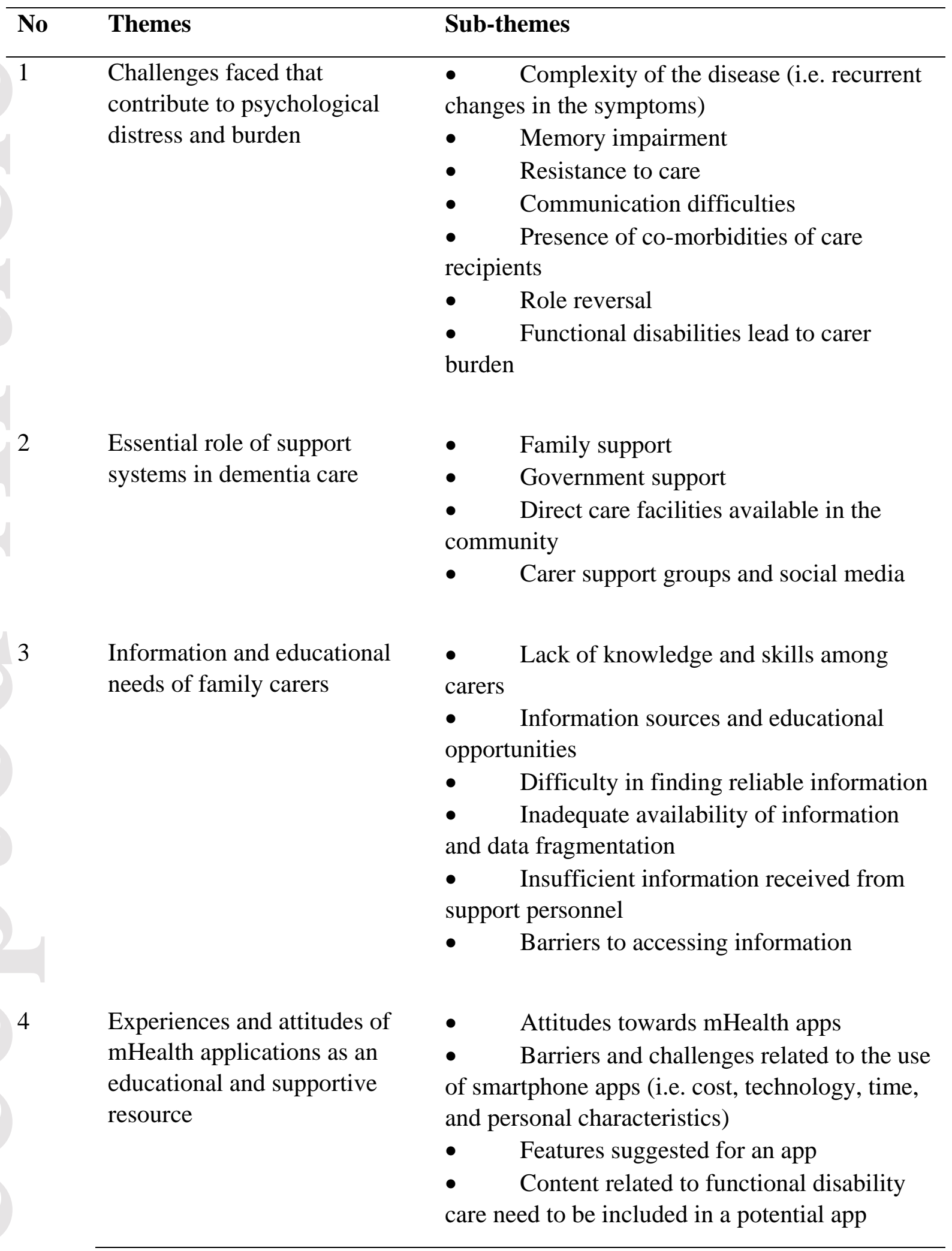

This article is protected by copyright. All rights reserved. 